\title{
Estudos RBBFP
}

\section{Memorial de formação escrito no decorrer da prática docente: aprendizagens sobre alfabetização e letramento*}

Mayra Prates Albuquerque

Lourdes Maria Bragagnolo Frison

Gilceane Caetano Porto

\section{Resumo}

Tem como objetivo apresentar a pesquisa acerca das aprendizagens realizadas por uma acadêmica do curso de licenciatura em Pedagogia, descritas em um memorial reflexivo, enquanto bolsista do Programa Institucional de Bolsas de Iniciação a Docência (Pibid). Para análise do memorial de formação escrito pela bolsista ao longo de sua atuação no programa, utilizou-se a técnica de análise de conteúdo, da qual emergiram duas diferentes categorias: a) contribuições do Pibid na formação acadêmica; b) efeitos do Pibid na aprendizagem dos alunos atendidos pelo programa na escola de atuação. Conclui-se que a bolsista realizou atividades estratégicas que potencializou sua aprendizagem, como também estimulou a aprendizagem dos alunos da escola envolvidos no programa.

Palavras-chave: Programa de Iniciação à Docência; memorial; formação.

* Projeto financiado pela Coordenação de Aperfeiçoamento de Pessoal de Nível Superior (Capes). 


\section{Abstract \\ Written formation memorial kept alongside teaching practice: different kinds of learning about alphabetization and literacy}

This article aims to present a review about the different kinds of learning achieved by an academic of Pedagogy, described in a reflective memorial kept alongside her participation as an intern of the Programa Institucional de Bolsas de Iniciação à Docência (Pibid - Institutional Scholarship Program for Teacher Initiation). In order to analyze the formation journal, which was written by the intern throughout the program, the content analysis technique was used. Based on this analysis, two different categories emerged: a) contributions of Pibid to the academic formation; and b) effects of Pibid on the learning of students attending the participating schools of the program. It is possible to conclude that the intern developed strategic activities that potentiated her learning, as well as encouraged the learning of the students involved in the program.

Keywords: Institutional Scholarship Program for Teacher Initiation (Pibid); memorial; formation.

\section{Introdução}

De acordo com a Coordenação de Aperfeiçoamento de Pessoal de Nível Superior (Capes), o Programa Institucional de Bolsas de Iniciação à Docência (Pibid) foi criado pelo governo federal com o objetivo de aperfeiçoar e valorizar a formação de professores da educação básica a partir da concessão de bolsas a alunos, supervisores e coordenadores envolvidos nos projetos desenvolvidos nas instituições de ensino superior. Nacionalmente os projetos buscaram possibilitar que os estudantes das licenciaturas se inserissem nas escolas públicas no percurso da formação acadêmica, desenvolvendo atividades didático-pedagógicas para qualificar a docência. Alguns dos principais objetivos do Pibid são incentivar a formação de docentes em nível superior para a educação básica; elevar a qualidade da formação inicial de professores nos cursos de licenciatura; promover a integração entre educação superior e educação básica; inserir os licenciandos no cotidiano de escolas da rede pública de educação; e investir na articulação entre teoria e prática necessárias à formação dos docentes, elevando a qualidade das ações acadêmicas dos universitários de diferentes áreas de conhecimento.

A instituição em que a pesquisa foi desenvolvida iniciou sua participação no Pibid em 2007. No primeiro projeto institucional apresentado à Capes, participavam quatro licenciaturas. No ano de 2009, a instituição em resposta ao Edital no 2/2009 inscreveu um projeto do qual fizeram parte os cursos de licenciatura em Letras, Filosofia, 
Ciências Sociais, Teatro, História e Pedagogia. Cada uma das licenciaturas mencionadas escreveu um subprojeto no qual foram descritas as ações para serem desenvolvidas em quatro escolas estaduais e, no caso da Pedagogia, em duas escolas municipais. Enfocaremos neste texto o subprojeto da Pedagogia.

O Pibid Pedagogia conta com 20 bolsistas de iniciação à docência comumente chamadas de pibidianas ${ }^{1}-, 2$ supervisoras que são docentes nas escolas envolvidas no projeto e 2 coordenadoras de área que atuam como professoras da universidade. O foco desse grupo é o trabalho interdisciplinar em classes de alfabetização. Dessa forma, as leituras realizadas ao longo do programa são direcionadas para a área de alfabetização e letramento, objetivando fortalecer os conhecimentos dos acadêmicos a respeito da teoria e prática pedagógica realizadas no espaço escolar, em uma constante interação com professores, equipe diretiva e alunos. Essas ações buscam oportunizar às crianças envolvidas uma aprendizagem mais significativa e plena, contribuindo assim para uma cultura de sucesso escolar.

Na universidade, atualmente uma das grandes reclamações por parte dos acadêmicos das licenciaturas é a falta de contato durante a formação com o ambiente escolar. Mesmo com as determinações normalmente estabelecidas pelas diretrizes curriculares do curso de Pedagogia (2006), o currículo é organizado de modo que as disciplinas práticas são oferecidas somente nos últimos semestres do curso, o que de certa forma compromete a formação dos acadêmicos ao impossibilitar a articulação entre teoria e prática desde o início da graduação, tornando a formação inicial insuficiente para dar conta das diversas especificidades inerentes aos processos de ensino e de aprendizagem. Nesse sentido, Barreiro e Gebran (2006, p. 22) enfatizam que, para Borssoi,

\footnotetext{
a articulação da relação teoria e prática é um processo definidor da qualidade da formação inicial e continuada do professor, como sujeito autônomo na construção de sua profissionalização docente, porque lhe permite uma permanente investigação e a busca de respostas aos fenômenos e às contradições vivenciadas.
}

O Pibid Pedagogia surgiu como uma possibilidade de diminuir a dicotomia existente entre a teoria e a prática, possibilitando a inserção e atuação dos licenciandos no cotidiano das escolas envolvidas. As ações desenvolvidas pelas bolsistas pibidianas envolviam toda a complexidade do trabalho pedagógico requerido a um docente dos anos iniciais do ensino fundamental. O cotidiano das acadêmicas de Pedagogia repleto de suposições sobre a prática pedagógica passou a se materializar por meio da realização de estudos, elaboração e desenvolvimento de planejamentos, avaliações diagnósticas e processuais e reflexões sobre a prática. Finalmente, as estudantes passaram a ter uma escola real, com alunos reais para tematizar, pensar e compartilhar saberes entre professores da universidade e da escola. mente com mulheres, desde bolsistas a supervisoras coordenadoras e professoras.
A fim de sistematizar os conhecimentos construídos ao longo da
experiência com a iniciação à docência, as bolsistas foram estimuladas 
a registrar por meio de memoriais reflexivos estabelecendo um diálogo entre a formação inicial e continuada no exercício de práticas educativas (Frison; Porto, 2013) nos quais registraram suas primeiras vivências no papel de docente dos anos iniciais do ensino fundamental. Nesses memoriais, encontraram-se as explicações das razões que levaram as bolsistas a escolherem o curso de Pedagogia, bem como sua inserção no Pibid. Este artigo apresenta a análise de um dos vinte memoriais escritos pelas alunas.

\section{Metodologia}

Optou-se pelo uso de memoriais de autoformação como fonte de registro e reflexão das bolsistas por se tratar, segundo Nogueira (2008), de instrumento de produção de dados, que se revelou como um dispositivo valioso para compreender os processos formativos. Passeggi (2006, p. 206) também defende essa ideia ao destacar que "o objetivo dos memoriais é promover uma atitude reflexiva sobre as experiências profissionais, adquiridas antes e durante a graduação".

Para o estudo desse memorial, utilizou-se a técnica de análise de conteúdo. Trata-se de uma metodologia de pesquisa utilizada para descrever e interpretar o conteúdo de todos os tipos de documentos e textos. Essa análise conduz a descrições sistemáticas qualitativas e ajuda a reinterpretar as mensagens e a atingir uma compreensão de seus significados em um nível que vai além de uma leitura comum. A realização da análise de conteúdo seguiu a metodologia que é composta por cinco etapas: preparação das informações; unitarização ou transformação do conteúdo em unidades; categorização ou classificação das unidades em categorias; descrição; e interpretação (Moraes, 1999).

No percurso da análise dos dados coletados, emergiram indicadores referentes às contribuições que o Programa de Iniciação à Docência do curso de Pedagogia proporcionou para a formação inicial da acadêmica em questão, a qual registrou suas aprendizagens no memorial que foi objeto de investigação deste artigo. Destaca-se que se iniciou a análise por um dos memoriais, para em um segundo momento examinar os demais. Compreende-se que a escolha do registro das aprendizagens se deu na forma de memorial porque, segundo Frison e Abrahão (2012, p. 45),

é o processo, bem como a resultante da rememoração com reflexão sobre fatos narrados - oralmente e/ou por escrito - que formem uma trama (um enredo) com sentido para o sujeito da narração, com a intenção, pois haverá sempre uma intencionalidade, de clarificar aspectos, dimensões e momentos da própria formação.

Infere-se que o memorial estimulou as alunas a vivenciarem o momento da elaboração de sua narrativa como um componente formativo essencial, portanto, elas tomaram consciência de que a escrita do memorial era um elemento primordial para a compreensão da própria formação. 
A partir da análise desse memorial, emergiram as seguintes categorias: a) contribuições do Pibid Pedagogia na formação acadêmica e b) efeitos do Pibid na aprendizagem dos discentes, as quais se analisam na sequência deste texto. Ao longo dessas duas categorias, foram inseridos indicadores que dizem respeito à relação entre teoria e prática e os benefícios provenientes das oficinas pedagógicas realizadas pelo Pibid, as quais objetivaram o aperfeiçoamento da formação.

\section{Contribuições do Pibid Pedagogia na formação acadêmica}

As contribuições do Pibid iniciaram com a articulação entre teoria e prática - pode-se dizer que a coordenação do Pibid do curso de Pedagogia, desde o início de sua organização em 2009, priorizou a inserção de acadêmicas de diferentes semestres em ambientes de sala de aula por entender que esse é um espaço de fundamental importância para o pleno desenvolvimento profissional das estudantes. Enfatizam muitas vezes que a prática pedagógica é indispensável, mas não pode ser desvinculada de estudos teóricos. Esse entendimento não somente fundamentou o trabalho desenvolvido pelo grupo como também permitiu que no decorrer das práticas pedagógicas fossem realizadas pesquisas sobre a legislação e orientação para o trabalho com as crianças de seis anos no ensino fundamental de nove anos; leituras e estudos de livros e artigos sobre alfabetização, letramento e organização do trabalho pedagógico; e análise de jogos e materiais didáticos para uso em classes de alfabetização. Todas as ações confluíram para permitir que as práticas fossem refletidas no sentido da práxis educativa (Freire, 2009). Considerando essas constatações, a acadêmica revelou em seu memorial,

\begin{abstract}
que são muitos os saberes aprendidos e vivenciados nas idas à escola duas vezes por semana. As leituras que fazemos acrescentam muito à nossa formação, já que estes sempre são textos em que a teoria possibilita a prática em sala de aula. Quero dizer que os textos não são alheios ao nosso trabalho na escola, ao contrário, estão sempre articulados, possibilitando-nos que leiamos já pensando em colocar em prática tais aprendizados [...] (Silva, 2013, p. 169-170)
\end{abstract}

Tendo presentes essas considerações entre prática e teoria, destaca-se que, para Madalena Freire (1996, p. 14), "não existe prática sem teoria, como também não existe teoria que não tenha nascido de uma prática." Com essa concepção, a autora faz alusão a uma reflexão que conduz o indivíduo a uma ação transformadora, fazendo com que ele gere novas práticas a partir de conhecimentos apreendidos.

Esse processo de modificação da prática pedagógica é mencionado pela bolsista quando afirma que, por meio dos diferentes estudos feitos, foi possível planejar e desenvolver atividades diversificadas que oportunizaram não apenas experiências em torno do ato de ser professor, como também fortaleceram a compreensão de conhecimentos metodológicos. 
Todas essas atividades foram pensadas após os estudos teóricos que realizei no Pibid, pois, até então, não havia pensado nessas imensas possibilidades de trabalho. Pude compreender o quanto é importante que o professor esteja atento às pequenas oportunidades que aparecem no dia a dia que possibilitam que se faça uma escrita e uma leitura mais espontâneas, mostrando o efetivo uso dessas diversas formas de comunicação na sociedade. Isso transformou o meu trabalho em sala de aula, possibilitando desenvolver um trabalho muito mais interessante, prazeroso e significativo [...] (Silva, 2013, p.170-171)

Nessa mesma perspectiva, Franco (2008, p. 123) salienta que "será preciso que os processos formativos de docentes absorvam a dimensão experimental, não mais separando teoria e prática, mas mergulhando desde o início o aluno e o formador em situação de mediação dos confrontos da prática, buscando a significação das teorias". Marques (2000, p. 93) corrobora afirmando que "não se fará ensino de relevância social através de práticas artificialmente induzidas, de práticas provocadas ou de práticas que não tenham relação com as experiências de vida e trabalho dos alunos" [...]. Partilhando dessa concepção, o trabalho realizado no Pibid Pedagogia buscou durante todo o seu desenvolvimento oferecer aos alunos práticas que tivessem relação com as situações da vida social.

A acadêmica escreveu em seu memorial os benefícios trazidos pelas oficinas pedagógicas realizadas no Pibid Pedagogia. Para ela, esses encontros permitiram ampliar saberes sobre diferentes áreas de conhecimento, por exemplo, a área de matemática:

[...] o contato com a oficina de jogos boole para mim foi fascinante, pois através desses jogos aprendemos brincando e a partir deles pude perceber que o ensino da matemática torna-se muito mais significativo, simples e lúdico. [...] esse aprendizado foi de fundamental importância para minha formação enquanto educadora, pois a partir do contato que tive com os jogos pude conhecer e refletir sobre outras maneiras de tornar o ensino da matemática mais atrativo aos alunos, além de ser um meio eficiente para desenvolver o raciocínio lógico das crianças. (Silva, 2013, p.171).

Anastasious e Alves (2003, p. 96) defende o uso de oficinas como meio de qualificação docente por se constituírem espaços adequados para realizar discussões das práticas e construir novas estratégias e define as oficinas como lugares para "[...] pensar, descobrir, reinventar, criar e recriar, favorecido pela forma horizontal, na qual a relação humana se dá".

A bolsista registrou diversos momentos que revelam a importância das experiências para a formação inicial, pois possibilitaram aprendizagens que, segundo ela, não foram desenvolvidas ao longo do curso de graduação e são consideradas importantes para o exercício da docência. No contexto da relação entre teoria e prática, das oficinas de formação e do investimento feito pela aluna, pode-se afirmar que ela internalizou conhecimentos que a fortaleceram para constituir-se uma professora comprometida. Ela revelou ainda estar mais atenta com a aprendizagem dos alunos, tornando-se uma profissional mais crítica e reflexiva diante da sua própria atuação em sala de aula. 


\section{Efeitos do Pibid na aprendizagem dos alunos da escola}

O trabalho desenvolvido pelas pibidianas nas escolas tem ênfase na perspectiva teórica de Emília Ferreiro, a qual, desde os anos 80, vem revolucionando o modo pelo qual compreendemos o processo de alfabetização. A autora constatou que "as crianças tendem espontaneamente a pensar, e toda a proposta pedagógica que as obriguem a renunciar a compreender dificulta a aprendizagem." (Ferreiro, 1993, p. 35).

As alunas do Pibid Pedagogia têm desenvolvido um trabalho pautado na ideia de que, para além da necessidade de alfabetizar, é preciso letrar, que de acordo com Soares (2004, p. 18) tem origem do vocábulo literacy, palavra de origem inglesa adaptada ao português por meio de uma tradução diretamente do termo originário, denotando "o resultado da ação de ensinar ou de aprender a ler e escrever: o estado ou a condição que adquire um grupo social ou um indivíduo como consequência de ter-se apropriado da escrita". Partindo dessa ideia, buscou-se realizar práticas que favorecessem o aluno não apenas a compreender o sistema de escrita alfabética, mas que também possibilitassem a inserção na escola de textos que circulam na sociedade, pois "a escrita é importante na escola, porque é importante fora dela e não o contrário" (Ferreiro, 2001, p. 33). Compartilhando dessa concepção, o trabalho desenvolvido pelo Pibid considera o aluno como sujeito ativo de seu processo de alfabetização. Ao longo do processo de aquisição da leitura e da escrita, a criança está constantemente elaborando hipóteses, conflitando seus conhecimentos com os dos colegas. As práticas que permitem que as crianças pensem sobre como se escreve determinado texto ou palavra contribuem para que elas formulem hipóteses, embora provisórias, mas que colaborem para a formação de um sujeito autônomo nos processos de aquisição da leitura e da escrita.

Tendo em vista a compreensão de que a aquisição da linguagem escrita se dá por meio da interação do sujeito (criança) com o objeto de conhecimento (leitura e escrita), é importante salientar que a familiaridade da criança com esses objetos sociais varia muito de acordo com o contato que ela tem desde antes da entrada na escola. Por isso, tem-se defendido cada vez mais a importância do papel do professor em compreender quais os conhecimentos que as crianças têm sobre a leitura e a escrita quando chegam à escola, especialmente no primeiro ano de escolarização. A realização de avaliações diagnósticas pelo professor dos anos iniciais com os alunos permite que ele acompanhe o processo de aquisição da leitura e da escrita desde o momento em que a criança chega à escola. Os dados obtidos a partir da avaliação diagnóstica (Maruny et al., 2001; Ferreiro, 1988; Nemirovsky, 2002) servem de guia para a organização do trabalho pedagógico em classes de alfabetização. Seguindo essas orientações teóricas, as bolsistas do Pibid Pedagogia realizaram, desde as primeiras semanas de aula, a avaliação diagnóstica dos conhecimentos linguísticos de seus alunos. Para isso, cada bolsista teve que estudar e compreender 
como se dá esse processo. Pela experiência relatada, esse procedimento foi de extrema importância, porque ajudou a bolsista a compreender quais são os conhecimentos prévios que os alunos possuem sobre a escrita e quais as práticas de escrita que vivenciam no cotidiano. Assim, todas as bolsistas realizaram a avaliação diagnóstica no início e no fim do ano letivo nas turmas de $1^{\circ}$ e $2^{\circ}$ ano da escola em que o programa foi desenvolvido a fim de conhecerem e compreenderem quais são os níveis de alfabetização dos alunos e, a partir disso, organizar o trabalho pedagógico de forma que contribuísse com o propósito de introduzir e/ou consolidar os conhecimentos necessários para que os alunos avançassem em seus níveis de compreensão do sistema de escrita e, na medida do possível, alcançassem o objetivo maior que seria o de se tornarem sujeitos alfabetizados.

As entrevistas da avaliação diagnóstica foram realizadas individualmente com os alunos das turmas dos $1^{\circ}$ e $2^{\circ}$ anos. As tarefas solicitadas às crianças foram elaboradas a partir dos estudos de Maruny et al. (2001) e Grossi (2007) e compreenderam a escrita do nome, a escrita de quatro palavras e uma frase, a escrita de todas as letras do alfabeto e de palavras que iniciassem com essas letras. Além disso, foram disponibilizados cartões que continham imagem e texto e outros com imagem e legenda, para que a partir do contato com esses cartões o aluno pudesse estabelecer relações entre a imagem contida e o conteúdo escrito. No final do ano letivo mais uma avaliação diagnóstica foi realizada, com o objetivo de verificar os conhecimentos que haviam sido construídos pelos alunos.

Encontram-se na Tabela 1 os resultados obtidos ao longo do ano letivo em uma turma de $2^{\circ}$ ano, na qual a bolsista desenvolveu seu trabalho juntamente com a professora titular da turma. Faz-se importante esclarecer que as testagens foram feitas em anos distintos, devido a uma greve das escolas municipais que acarretou em um ano letivo que se estendeu ao ano civil. Segue o resultado da avaliação da turma.

Tabela 1 - Níveis de Aquisição da Leitura e da Escrita da Turma em que a Bolsista Desenvolveu seu Trabalho

\begin{tabular}{|l|l|l|}
\hline \multicolumn{3}{c}{ Avaliação diagnóstica } \\
\hline Níveis de aquisição da leitura e escrita & \multicolumn{1}{|c}{2011} & 2012 \\
\hline Nível 1/Pré-silábico I & 12 alunos & 0 alunos \\
\hline Nível 2/Pré-silábico II & 2 alunos & 5 alunos \\
\hline Nível 3/Silábico & 2 alunos & 1 aluno \\
\hline Nível 4/Silábico-alfabético & 4 alunos & 7 alunos \\
\hline Nível 5/Alfabético & 0 alunos & 6 alunos \\
\hline
\end{tabular}


No início do trabalho no ano de 2011, 12 alunos encontravam-se no primeiro nível, ou seja, no pré-silábico I. Esses alunos demonstravam que suas aprendizagens correspondiam ao nível em que ocorrem as primeiras escritas - que nada mais são do que rabiscos, desenhos e letras. Nessa fase, o significado de uma escrita pode mudar várias vezes dependendo da intenção do autor. Dessa forma, a interpretação só pode ser feita por ele mesmo, a leitura é instável e a palavra pode ser escrita de diversas maneiras, já que não há uma relação entre o som e a grafia. A quantidade de letras varia de acordo com o tamanho do objeto que está sendo escrito. As informações contidas tanto nesse nível quanto nos demais foram retiradas dos autores Maruny, Morillo e Teixidó (2001).

No nível 2, ou seja, no pré-silábico II, havia dois alunos. Nessa fase, eles demonstraram iniciar uma tentativa em criar diferenciações entre os grafismos produzidos. A forma desses grafismos é mais próxima das letras que normalmente são as do repertório do aluno, como as que compõem seu nome próprio, por exemplo. Nesse nível, a correspondência entre a escrita e o nome ainda é global.

Dois alunos se encontravam no nível 3, denominado silábico, tentando estabelecer relações entre o som e a grafia das palavras. Nessa fase, foi possível perceber a criança começando a utilizar um sinal gráfico para representar o som de uma sílaba, porém, qualquer letra pode servir para qualquer som nessa etapa e as letras não são utilizadas com valor sonoro convencional. Quando ocorre de o aluno utilizar apenas vogais para representar as sílabas orais, pode acontecer de palavras diferentes serem escritas de formas iguais, contrariando a hipótese anterior e gerando conflitos. Com o intuito de solucionar esses conflitos, é comum que a criança empregue mais letras no meio ou no final da palavra. Essa etapa é de fundamental importância para o desenvolvimento da aprendizagem, já que é nessa fase que a criança começa a perceber a relação existente entre a pauta sonora e a escrita. É o momento que marca a fonetização da escrita e que é considerado um grande avanço em relação às hipóteses anteriores.

Na hipótese silábico-alfabética (nível 4) havia quatro alunos. Eles demonstraram que iniciavam um período de transição entre hipóteses silábica e alfabética. Percebeu-se que nessa etapa as crianças avaliadas ainda não haviam abandonado totalmente a hipótese anterior. No entanto, começaram a empregar mais letras à escrita, tornando-a mais próxima do nível alfabético, no qual os sons são registrados com mais de uma letra.

Por fim, chega-se à hipótese alfabética. Não havia nenhuma criança no início do trabalho do Pibid nesse nível de conceitualização da escrita. Segundo a teoria da Psicogênese da língua escrita, nessa etapa a criança constrói a concepção do sistema de escrita fazendo análise sonora da palavra a ser grafada e inicia o processo de separação das palavras nas frases. Pode-se dizer que nesse momento a criança já compreendeu o sistema de escrita, tem segurança em suas produções por saber que o leitor entenderá seu texto, mas começam a aparecer as dificuldades no domínio das normas ortográficas.

É possível perceber que o trabalho desenvolvido permitiu avanços significativos nos níveis de compreensão dos alunos sobre a linguagem 
escrita na qual estavam inseridos, na medida em que todos os alunos envolvidos no trabalho apresentaram avanços de nível. Ao fim do ano letivo, não havia mais alunos no nível pré-silábico. Anteriormente ao início do trabalho, não havia alunos no nível alfabético; no entanto, ao término da intervenção, constatou-se haver seis crianças que conseguiram alcançar o último nível de aquisição da escrita, ou seja, foram alfabetizados no decorrer do ano letivo. Consideram-se esses resultados exitosos, pois, anteriormente ao início da intervenção, o número de alunos que não conseguiam alcançar os níveis silábico-alfabético e alfabético era muito maior devido a vários fatores que caracterizam a escola por apresentar um Índice de Desenvolvimento da Educação Básica (Ideb) abaixo da média. Deve-se levar em consideração que a escola envolvida situa-se em uma zona de periferia, em que a maior parte dos alunos tem pouca inserção na cultura escrita, não tendo como hábito desenvolver práticas de leitura e escrita, tampouco acesso a diversos materiais como livros, revistas e jornais. Dessa forma, para a maioria desses alunos, o primeiro contato com os diversos materiais que circulam na sociedade é dado somente após a sua inserção na escola.

Levando em consideração essas especificidades, foi organizado um projeto denominado "Um carteiro que desvenda histórias", o qual articulava gêneros textuais com contos clássicos na tentativa de trabalhar o processo de aquisição da leitura e da escrita de uma forma diferenciada, priorizando a escrita espontânea de cada aluno, mediante propostas didáticas contextualizadas e articuladas com o cotidiano dos discentes, partindo de uma perspectiva que considera de fundamental importância o trabalho com a realidade de vida dos alunos e valoriza os processos históricos, culturais e sociais da comunidade em que eles estão inseridos.

Sendo assim, as práticas desenvolvidas pelas bolsistas na escola procuravam romper com a lógica tradicional de educação e priorizavam a história de vida de cada aluno articulando esta com as atividades realizadas, o que as tornam, de fato, significativas.

\section{Considerações finais}

A partir da análise do memorial da pibidiana foi possível perceber que o Programa Institucional de Bolsas de Iniciação à Docência possibilitou inúmeras aprendizagens tanto para ela quanto para os alunos inseridos na escola em que este trabalho foi desenvolvido. O processo de aprender é hoje entendido como uma construção que requer papel ativo por parte dos alunos. Sob essa perspectiva, tornou-se imprescindível que as pibidianas estivessem totalmente envolvidas nas atividades para que, por meio delas, conseguissem desenvolver a capacidade de aprender para ensinar, estabelecendo metas para a organização do planejamento e, além disso, aprendendo a diagnosticar o processo de aprendizagem da criança para nele poder intervir. Nesse sentido, as alunas bolsistas autorregularam suas aprendizagens, traçando atividades estratégicas que permitissem ao aluno 
aprender. Dessa forma, os alunos também alcançaram as aprendizagens desejadas para o processo de leitura e escrita.

A autorregulação da aprendizagem do grupo de pibidianas se fundamentou na reflexão consciente sobre o significado dos problemas que surgiram, tendo que a cada um deles decidir nova tomada de decisão em uma espécie de diálogo consigo mesmo, o que foi pontuado em cada uma das categorias de análise.

A primeira categoria denominada "Contribuições do Pibid na formação acadêmica" evidenciou as aprendizagens que a bolsista desenvolveu durante o período em que participou do programa. Para sua formação inicial, essas aprendizagens não se limitaram apenas as teorias estudadas, mas também aos conhecimentos adquiridos com a possibilidade de estar inserida em uma escola, trabalhando em sala de aula juntamente com a professora titular da turma, vivenciando o dia a dia da escola e colocando em prática a teoria que foi estudada. De acordo com a pibidiana, essa oportunidade só é oferecida pelo programa, já que na graduação não são oferecidas oportunidades semelhantes.

A segunda categoria denominada "Efeitos do Pibid na aprendizagem dos discentes" mostrou que esta foi evidenciada na turma em que a pibidiana esteve inserida. Isso foi possível a partir da realização de um trabalho diferenciado, que procurava levar em conta os interesses e a realidade desses alunos, desenvolvendo um ensino mais interessante e significativo, oportunizado por meio de diferentes gêneros textuais.

A avaliação diagnóstica permitiu conhecer os níveis de compreensão da língua em que cada aluno se encontrava no início do ano letivo, para que, a partir disso, fossem desenvolvidas atividades e estratégias que possibilitassem o avanço de cada um deles. No final do trabalho, com a realização de mais uma avaliação diagnóstica, constatou-se que realmente a intervenção desencadeou avanços na compreensão do sistema de escrita para todos os alunos que participaram do programa.

Pode-se concluir que o Pibid é um programa inovador no âmbito da educação, pois, por meio dele, os alunos das licenciaturas têm a oportunidade de estar inseridos nas escolas, em contato com a realidade escolar desde o início da graduação, qualificando desse modo sua formação inicial e ainda contribuindo para uma melhor qualidade de ensino nas escolas públicas ao desenvolver metodologias inovadoras.

\section{Referências bibliográficas}

AMORIM, I. B; SANTOS, G. A. C; VIRGÍLIO, J. M. O memorial na formação do pedagogo: narrativas de um processo dialógico. Disponível em: <http://www.cairu.br/revista/arquivos/artigos/2012_2/8_ MEMORIAL_FORMACAO_PEDAGOGO_Geisa_105_118.pdf $>$. Acesso em: 21 jul. 2013. 
ANASTASIOU, L. G. C; ALVES, L. P. Processo de ensinagem na universidade: pressupostos para as estratégias de trabalho em aula. Joinville: Univille, 2003, p. 96.

BARREIRO, Iraíde Marques de Freitas; GEBRAN, Raimunda Abou. Prática de ensino e estágio supervisionado na formação de professores. São Paulo: Avercamp, 2006.

BORSSOI, B. L. O estágio na formação docente: da teoria a prática, ação-reflexão. In: SIMPÓSIO NACIONAL DE EDUCAÇÃO; SEMANA DA PEDAGOGIA, 20., 2008, Cascavel. Anais...Cascavel: Unioeste, 2008. Disponível em: < http://www.unioeste.br/cursos/cascavel/pedagogia/ eventos/2008/1/Artigo\%2028.pdf>. Acesso em: 10 maio 2013.

BRASIL. Ministério da Educação (MEC). Coordenação de Aperfeiçoamento de Pessoal de Nível Superior (CAPES). Programa Institucional de Bolsa de Iniciação à Docência. Disponível em: < http:// www.capes.gov.br/educacao-basica/capespibid>. Acesso em: 23 abr. 2013.

BRASIL. Coordenação de Aperfeiçoamento de Pessoal de nível Superior (CAPES). Diretoria de Educação Básica Presencial (DEB). Programa Institucional de Bolsa de Iniciação à Docência - PIBID: Edital n. 02/2009. Disponível em: < http://www.ufgd.edu.br/prograd/programas/ pibid-selecao-2010/edital-capes-deb-no-02-2009-2013-pibid-orientaras-instituicoes-interessadas-a-apresentarem-propostas-para-aselecao-de-projetos-com-vistas-a-concessao-de-bolsas-de-estimulo-adocencia>. Acesso em: nov. 2013

FERREIRO, Emília. Com todas as letras. São Paulo: Cortez, 1993.

FERREIRO, Emília. Cultura escrita e educação. Porto Alegre: ARTMED, 2001.

FERREIRO, Emília. Psicogênese da língua escrita. Porto Alegre: Artes Médicas, 1988.

FRANCO, Maria Amélia Santoro. Entre a lógica da formação e a lógica das práticas: a mediação dos saberes pedagógicos. Educação e Pesquisa, v. 34, n. 1, jan./abr. p. 109-126. Disponível em: < http://www. redalyc.org/articulo.oa?id=29811337005> . Acesso em: 31 jan. 2014.

FREIRE, M. Observação, Registro e reflexão: instrumento metodológico I. 2 ed. São Paulo: Espaço Pedagógico, 1996.

FREIRE, P. Pedagogia do oprimido. Rio de Janeiro: Paz e Terra, 2009. 
FRISON, Lourdes Maria Bragagnolo; ABRAHÃO, Maria Helena Menna Barreto. Formação de professores, memórias e narrativas. In: ARAÚJO, Mairce da Silva; MORAIS, Jacqueline de Fátima dos Santos (orgs.). Vozes da educação: formação de professores, narrativas, políticas e memórias. Rio de Janeiro: EdUERJ, 2012. p. 41-58.

GROSSI, Esther P. Prova Ampla. Porto Alegre: GEEMPA, 2007.

MARQUES, M. O. A formação do profissional da educação. 3. ed. Ijuí: Unijuí, 2000.

MARUNY, L. Curto; MORILLO, M. M; TEIXIDÓ, M. M. Escrever e ler: como as crianças aprendem e como o professor pode ensiná-las a escrever e a ler. v. 1, 2. Porto Alegre: Artmed, 2001.

MORAES, R. Análise de conteúdo. Revista Educação, Porto Alegre, v. 22, n. 37, 1999.

NEMIROVSKY, Myriam. O ensino da linguagem escrita. Porto Alegre: Artmed, 2002

NOGUEIRA, Eliane Greice Davanço et al. A escrita de memoriais a favor da pesquisa e da formação. In: SOUZA, Elizeu Clementino; MIGNOT, Ana Chrystina Venâncio. (Org.). Histórias de vida e formação de professores. Rio de Janeiro: Quartet, FAPERJ, 2008.

PASSEGGI, M. C. A formação do formador na abordagem autobiográfica. A experiência dos memoriais de formação. In: SOUZA, E. C. ABRAHÃO, M. H. M. B (Orgs.). Tempos, narrativas e ficções: a invenção de si. Porto Alegre: EDIPUCRS; EDUNEB, 2006, p. 206.

SILVA, J. Q. G. O memorial no espaço da formação acadêmica: (re) construção do vivido e da identidade. Perspectiva, Florianópolis, v. 28, n. 2, p. 601-624, jul./dez. 2010 Disponível em: <http://www. pucminas.br/imagedb/mestrado_doutorado/publicacoes/PUA_ARQ_ ARQUI20121016140628.pdf>. Acesso em: 6 mar. 2013.

SILVA, Mayra da. Minhas memórias durante o Pibid. In: FRISON, L. M. B.; PORTO. G.C. (Orgs). Diálogo entre a formação inicial e continuada através da escrita e autoformação. Pelotas: UFPel, 2013. p. 166-173.

SOARES, Magda. Letramento um tema em três gêneros. Belo Horizonte: Autêntica, 2004. 
Mayra Prates Albuquerque, acadêmica do nono semestre do curso de Licenciatura em Pedagogia da Universidade Federal de Pelotas (UFPel), Rio Grande do Sul, Brasil.

mayra_prates@hotmail.com

Lourdes Maria Bragagnolo Frison, doutora em Educação pela Pontifícia Universidade Católica do Rio Grande do Sul (PUC-RS), é professora adjunta do Departamento de Fundamentos Psicológicos da Educação, da Faculdade de Educação, da Universidade Federal de Pelotas (UFPel), Rio Grande do Sul, Brasil.

lfrison@terra.com.br

Gilceane Caetano Porto, doutora em Educação pela Universidade Federal de Pelotas (UFPel), é professora adjunta do Departamento de Ensino da Faculdade de Educação da UFPel, Pelotas, Rio Grande do Sul, Brasil.

gil.porto@terra.com.br

Recebido em 13 de setembro de 2013.

Aprovado em 17 de dezembro de 2013. 